\title{
Distributed Processing of Pain and Vibration by the Human Brain
}

\author{
Robert C. Coghill, ${ }^{1}$ Jeanne D. Talbot, ${ }^{1}$ Alan C. Evans, ${ }^{2}$ Ernst Meyer, ${ }^{2}$ Albert Gjedde, ${ }^{2}$ M. Catherine Bushnell, ${ }^{1}$ \\ and Gary H. Duncan ${ }^{1}$ \\ ${ }^{1}$ Centre de Recherche en Sciences Neurologiques and Faculté de Médecine Dentaire, Université de Montréal, Montreal, \\ Quebec, Canada H3C 3.57 and ${ }^{2}$ Positron Imaging Laboratories, McConnell Brain Imaging Center, Montreal Neurological \\ Institute, Montreal, Quebec, Canada H3A 2B4
}

Pain is a diverse sensory and emotional experience that likely involves activation of numerous regions of the brain. Yet, many of these areas are also implicated in the processing of nonpainful somatosensory information. In order to better characterize the processing of pain within the human brain, activation produced by noxious stimuli was compared with that produced by robust innocuous stimuli. Painful heat $\left(47-48^{\circ} \mathrm{C}\right)$, nonpainful vibratory $(110 \mathrm{~Hz})$, and neutral control $\left(34^{\circ} \mathrm{C}\right)$ stimuli were applied to the left forearm of righthanded male subjects. Activation of regions within the diencephalon and telencephalon was evaluated by measuring regional cerebral blood flow using positron emission tomography $\left({ }^{15} \mathrm{O}\right.$-water-bolus method).

Painful stimulation produced contralateral activation in primary and secondary somatosensory cortices (SI and SII), anterior cingulate cortex, anterior insula, the supplemental motor area of the frontal cortex, and thalamus. Vibrotactile stimulation produced activation in contralateral SI, and bilaterally in SII and posterior insular cortices. A direct comparison of pain and vibrotactile stimulation revealed that both stimuli produced activation in similar regions of $S I$ and SIl, regions long thought to be involved in basic somatosensory processing. In contrast, painful stimuli were significantly more effective in activating the anterior insula, a region heavily linked with both somatosensory and limbic systems. Such connections may provide one route through which nociceptive input may be integrated with memory in order to allow a full appreciation of the meaning and dangers of painful stimuli.

These data reveal that pain-related activation, although predominantly contralateral in distribution, is more widely dispersed across both cortical and thalamic regions than that produced during innocuous vibrotactile stimulation. This distributed cerebral activation reflects the complex nature of pain, involving discriminative, affective, autonomic, and motoric components. Furthermore, the high degree of interconnectivity among activated regions may account for the difficulty of eliminating pathological pain with discrete CNS lesions.

\footnotetext{
Received Aug. 5, 1993; revised Dec. 27, 1993; accepted Feb. 2, 1994.

We thank Sylvain Milot, Peter Neelin, Sean Marrett, and the staff of the McConnell Brain Imaging Centre and the Medical Cyclotron Unit for their technical assistance. This work was supported by the Medical Research Council of Canada R.C.C. was supported by an MRC fellowship.

Correspondence should be addressed to G. H. Duncan, D.D. S., Ph.D., Département de Stomatologie, Faculté de Médecine Dentaire, Université de Montréal, C.P. 6128, Succursale A, Montreal, Quebec, Canada H3C 3 J7.

Copyright (C) 1994 Society for Neuroscience $0270-6474 / 94 / 144095-14 \$ 05.00 / 0$
}

IKey words: pain, vibration, thalamus, positron emission tomography, human, primary somatosensory cortex, insula, secondary somatosensory cortex, heat, cingulate cortex]

An understanding of nociceptive processing in the human brain has remained elusive, perhaps because of the complexity and multiplicity of mechanisms supporting this essential sensory experience. Early observations by neurosurgeons led to the view that pain is a diencephalic phenomenon and that the telencephalon has little to do with pain perception (Head and Holmes, 1911; Penfield and Boldrey, 1937). These observations, however, were founded largely on the results of focal lesions and focal stimulation and did not examine the possibility that activation of multiple brain regions may be essential for the experience of pain. Modern theories of pain processing (Melzack and Casey, 1968; Price, 1988) acknowledge that multiple brain regions may likely play key roles in nociceptive processing and postulate that areas involved in discriminative aspects of tactile sensation, such as ventroposterior thalamus (VP) and primary somatosensory cortex (SI), are also involved in discriminative aspects of nociception, while medial areas of thalamus and their diffuse cortical projection sites - for example, frontal, cingulate, and insular cortices (Jones and Seavitt, 1974; Kaufman and Rosenquist, 1985; Royce and Mourcy, 1985; Friedman and Murray, 1986)-are involved in the affective aspects of nociception (Bowsher, 1957; Price and Dubner, 1977; Melzack, 1986).

This functional segregation has been supported by a limited number of lesion and stimulation studies in humans and monkey. Lesions to SI in monkey (Kenshalo et al., 1991) and to the region around secondary somatosensory cortex (SII) in human (Greenspan and Winfield, 1992) lead to deficits in pain discrimination. Further, localized pain has been evoked from microstimulation of the base of VP in humans (Dostrovsky et al., 1990; Lenz et al., 1993). In contrast, lesions to anterior cingulate or insular cortices in humans have been reported to alter affective responses to pain (Foltz and Lowell, 1962; Hurt and Ballantine, 1973; Berthier et al., 1988).

Nevertheless, the conspicuous paucity of nociceptive neurons in primary somatosensory pathways continues to raise doubts about the importance of these areas to pain perception. Although anatomical studies in primates show projections from regions of the dorsal horn that contain nociceptive neurons to parts of VP thalamus (Apkarian and Hodge, 1989; Craig, 1992), most investigations have yielded only a small percentage of neurons in VP that respond to noxious stimuli in the primate (Kenshalo et al., 1980; Casey and Morrow, 1983; Bushnell and Duncan, 
1987; Bushnell et al. 1993). Similarly, although regions of primate thalamus containing nociceptive cells project to SI and SII (Kenshalo et al., 1980; Friedman and Murray, 1986; Gingold et al., 1991; Rausell and Jones, 1991), relatively few nociceptive neurons have been identified in these cortical regions (Kenshalo and Isensee, 1983; Kenshalo et al., 1988; Dong et al., 1989).

Other data question the view that nociceptive processing in "extralemniscal" pathways is restricted exclusively to the affective/motivational aspects of pain perception. In awake monkeys we have found cells in the region of the thalamic nucleus parafascicularis (Pf) that respond differentially to perceptually liminal differences in noxious heat stimuli, and thus could provide a neural substrate for the discrimination of pain intensity (Bushnell and Duncan, 1989). Further, quantitative psychophysical data from a case study involving anterior capsulotomy indicate that lesions which interrupt thalamocortical projections to the anterior cingulate and frontal cortices reduce the perceived intensity of noxious heat stimuli (Talbot et al., 1993).

Recent advances in functional imaging now provide a powerful tool for addressing questions about cerebral mechanisms of pain in normal humans. These techniques allow a simultaneous assessment of activation within multiple brain regions, thereby providing global information unattainable in individual stimulation, lesion, or recording experiments. In an initial study using positron emission tomography (PET) to examine the regional distribution of cerebral blood flow (rCBF), we found that painful heat stimuli activate regions of SI and SII cortices, as well as area 24 in the anterior cingulate cortex - all contralateral to the stimulated arm (Talbot et al., 1991). We concluded that each of these regions may contribute substantially to discriminative aspects of nociception, since the experimental methods employed were designed to minimize the affective dimension of pain perception. I ssing similar stimulation and imaging techniques, Jones et al. (1991) replicated our finding of anterior cingulate activation and additionally reported contralateral activation at the level of thalamus - an area below the region scanned in our study. They did not, however, detect significant pain-related activation of SI or SII cortex, and thus proposed that one cortical site, the anterior cingulate cortex, is the sole representation of the "suffering" component of pain (Jones et al., 1991). To complicate this issue further, Apkarian et al. (1992) recently argued for a role of SI cortex in pain processing based on their observation of a decrease in $\mathrm{rCBF}$ in this region during a study of tonic heat stimulation using single photon emission computed tomography (SPEC'I).

The present study was undertaken, therefore, to address these disparate results by cxamining in more detail activation within the human brain during painful cutaneous heat stimulation. We sought to confirm the involvement of multiple cerebral cortical regions in the processing of pain and to test the specificity of pain-related activation by comparing it with that produced by robust tactile stimulation. Blood-flow studies have established that regions within SI and SII cortices are activated during vibrotactile stimulation (Fox et al., 1987; Meyer et al., 1991; Seit/ and Roland, 1993). Likewise, we have observed activation within the same regions during painful heat stimulation (Talbot et al., 1991). However, without a direct comparison of pain- and vibrotactile-related activity within the same subjects, few conclusions can be drawn concerning the relative locations or strengths of activation evoked by the two stimulus modalities.

A preliminary report of these data has been presented (Coghill et al., 1992).

\section{Materials and Methods}

Subjects. Nine right-handed pain-free male subjects between 20 and 35 years old (mean, 27 years) participated in this experiment. Subjects gave informed consent acknowledging that (1) they would be exposed to low doses of radiation and heat-induced pain, (2) the methods to be used and the risks involved were clearly explained and understood, and (3) they were free to withdraw from the experiment at any time without prejudice. All procedures were approved by the Ethics and Research Committee of the Montreal Neurological Institute and Hospital and were in accordance with the Declaration of Human Rights, Helsinki, 1975.

Stimulation procedures. Neutral $34^{\circ} \mathrm{C}$ thermal (Control), $47-48^{\circ} \mathrm{C}$ painful heat (Pain), and $110 \mathrm{~Hz}$ vibrotactile (Vibration) stimuli were employed as experimental conditions that were presented to the subjects during separate scans. Thermal stimuli were produced by a computercontrolled contact thermode with a rise time of $6^{\circ} \mathrm{C} / \mathrm{sec}$ (Larson et al., 1987), and $110 \mathrm{~Hz}$ vibrotactile stimuli were delivered by an electric vibrator (Daito, Osaka, Japan). Each device had a circular stimulating surface of $1 \mathrm{~cm}^{2}$, that was placed on the skin of the subject's left (nondominant) forearm.

During each $60 \mathrm{sec}$ scanning period, one of the three stimulus conditions (Control, Pain, Vibration) was presented to the subject. Stimuli were delivered at six marked locations $(3 \times 2$ matrix with interstimulus distance of $3 \mathrm{~cm}$ ) on the ventral surface of the forearm. In order to minimize sensitization or habituation that may result from repeated presentations of noxious heat (Price et al., 1983), stimuli were rotated among the six locations, with a $6 \mathrm{sec}$ presentation at each site followed by a $4 \mathrm{sec}$ interstimulus level. The painful heat was presented as a twostep pulse, in which the temperature was held at $47^{\circ} \mathrm{C}$ for $5 \mathrm{sec}$ and then raised to $48^{\circ} \mathrm{C}$ for $1 \mathrm{sec}$ (Talbot et al., 1991). This procedure maximizes neuronal responses to noxious heat while minimizing exposure to potentially injurious stimuli (Bushnell and Duncan, 1989; Maixner et al., 1989). The control and vibrotactile stimuli were presented to the same six spots of skin using identical sequencing and timing parameters as those employed during the noxious heat scans.

Quantitative psychophysical response procedures. All subjects participated in a practice session in which they were presented the same stimuli to be used during the PET scans. During this session, subjects were asked to rate all stimuli on a magnitude-estimation scale, with 0 denoting no sensation, 50 denoting pain threshold, and 100 signifying extreme pain (Talbot et al., 1991). Only subjects who showed no withdrawal response to the noxious heat stimuli and who reliably and differentially rated the neutral thermal, vibrotactile, and noxious heat stimuli were retained for the PET study.

PET scans. The relative distribution of cerebral blood flow (CBF) was evaluated using the $\mathrm{H}_{2}{ }^{15} \mathrm{O}$ bolus methodology of Fox and Mintun (1989) without arterial blood sampling. PET scans were obtained with the Scanditronix PC-2048 system, which provides 15 image slices 6.5 $\mathrm{mm}$ apart with a transverse image resolution of $4.6-6.4 \mathrm{~mm}$ and an axial resolution of 5.4-7.1 mm (Evans et al., 1989, 1991a,b).

Prior to the PET scan session, the subject's head was firmly secured by a custom-fitted foam headholder (Evans et al., 1991a), eye patches were placed to limit extraneous stimulation, and an infrared pulse oximeter was positioned on the right index finger to monitor heart rate. An intravenous catheter was inserted into the median vein of the right forearm for injection of the $\mathrm{H}_{2}{ }^{15} \mathrm{O}$ bolus and secured in such a way as to minimize discomfort during the PET scans. Subjects were instructed to remain still, attend to all the stimuli presented during each scan, and rate the mean intensity of those stimuli after each scan was completed. Their heads were then optimally positioned within the PET scanner; the most superior region scanned was never more than $2 \mathrm{~mm}$ inferior to the superior extreme of the cerebral cortex. Brain regions included within the scanned areas are displayed in Figure 1.

In order to minimizc possiblc anxicty-relatcd cerebral activation associated with the novelty of the measurement procedures (injection of radioactive tracer and operation of the PET camera), the first scan for each subject was designated a "sham." During these sham scans, physiological saline $(0.9 \%, 9 \mathrm{ml})$ was injected into the venous catheter, the $34^{\circ} \mathrm{C}$ control stimulus was applied in the standard fashion, and the scan procedures simulated as closely as possible.

Following the sham scan, six $60 \mathrm{sec}$ experimental scans were conducted, with at least 15 min between each scan to minimize effects of preceding stimuli and to allow the tracer concentration to decay to background levels. Scanning of each stimulus condition (Control, Pain, 


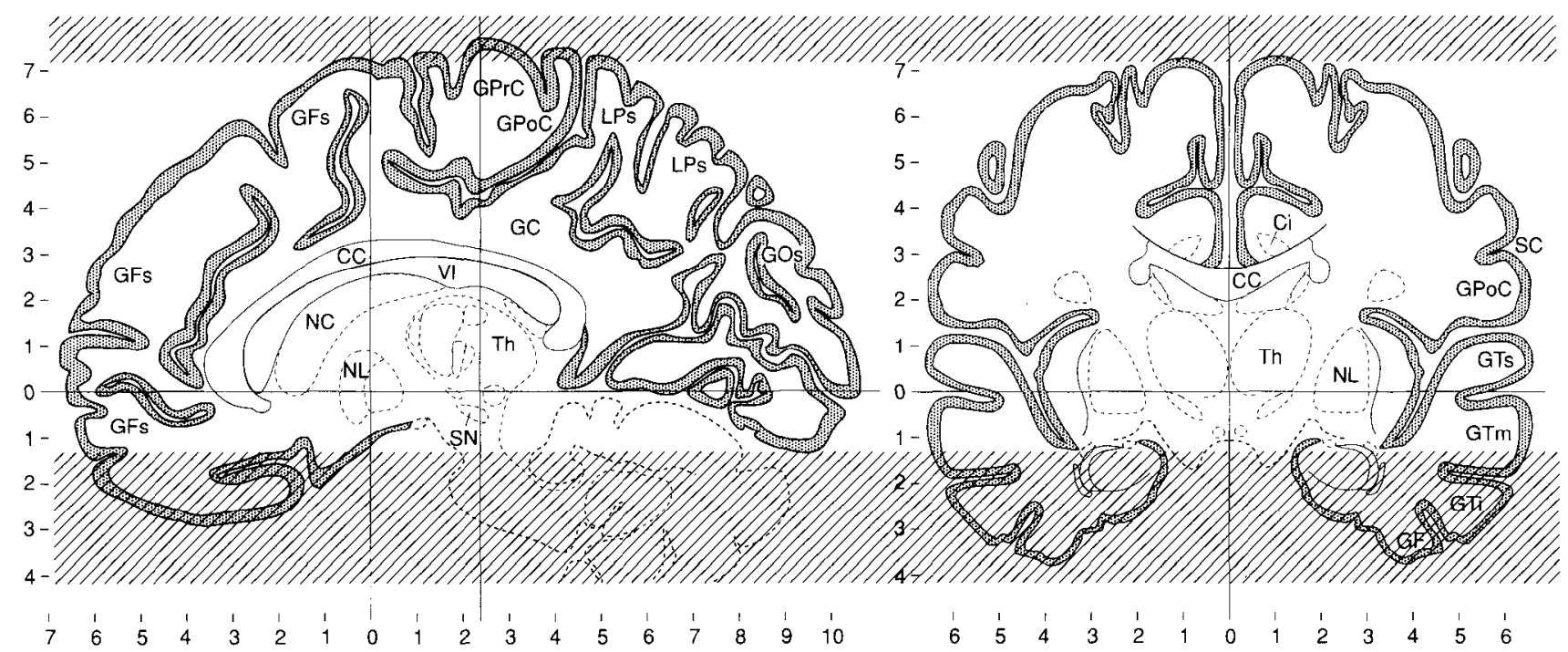

Figure 1. Brain regions examined by positron emission tomography. As can be seen in the sagittal (lefi) and coronal (right) sections, cerebral regions from the vertex of the parietal cortex to the inferior portions of the thalamus were scanned in all subjects. Structures within the hatched areas were not included in the analysis since not all subjects were scanned at these levels. Structures not fully examined include the amygdala, temporal poles, ventrolateral orbital frontal cortex, cerebellum, superior colliculus, and other inferiorly located regions (after Talairach and Tournoux, 1988). Abbreviations for Figures 1 and 6: $C C$, corpus callosum; $C i$, cingulum; $G C$, cingulate gyrus; $G F i$, inferior frontal gyrus; $G F m$, middle frontal gyrus; $G F s$, superior frontal gyrus; $G h$, parahippocampal gyrus; $G O b$, basal orbital gyri; $G O s$, superior occipital gyrus; $G P O C$, postcentral gyrus; $G P r C$, precentral gyrus; $G T i$, inferior temporal gyrus; $G T m$, middle temporal gyrus; $G T s$, superior temporal gyrus; $L P i$, inferior parietal lobule; $L P S$, superior parietal lobule; $N C$, caudate nucleus; $N L$, lenticular nucleus; $S C$, central sulcus; $S N$, substantia nigra; $T h$, thalamus; $V I$, lateral ventricle.

and Vibration) was performed twice, in a pseudorandom order. Heart rates were recorded at $15 \mathrm{sec}$ intervals throughout $1 \mathrm{~min}$ periods preceding, during, and following each scan. At the end of each scan, subjects gave a single rating for the mean intensity of the stimuli presented during that scan.

Magnetic resonance image scans. Each subject received an MRI scan during a separate session following the PET portion of the experiment. A Phillips $1.5 \mathrm{~T}$ Gyroscan was utilized to obtain 64,2 -mm-thick $T_{i}$ weighted multislice spin echo images (repetition time $T_{R}=550 \mathrm{msec}$; echo time $T_{t}=30 \mathrm{msec}$ ) for later reconstruction into the three-dimensional MRI volumc.

Image processing and analysis. PET images were smoothed with a $20 \mathrm{~mm}$ (full width, half-maximum) Hanning filter to minimize the effects of anatomical variability among subjects (Fox and Mintun, 1989). This has the effect of increasing the signal-to-noise ratio in the averaged image, but reduces the spatial resolution. Using a volumetric image registration procedure (Evans et al., 1989, 1991a), the MRI volume from each subject was aligned with the PET volumes. Both MRI and PET data were then remapped into a standardized stereotaxic coordinate system (Evans et al., 199 1a), using an orthogonal coordinate frame based on the anterior commissure-posterior commissural line as identified in the MRI volume (Evans et al., 1992).

Each PET volume was then normalized by dividing every voxel count by the mean value for all intracerebral voxels. For individual subjects, the normalized images from the two repetitions of the same stimulus condition were averaged to reduce variability. Different stimulus conditions were then subtracted from each other (voxel by voxel), and the relative mean state-dependent change $(\triangle \mathrm{CBF})$ volume was obtained by averaging these subtraction images across subjects. Identical stimulus conditions were also subtracted (Pain - Pain $_{1}$, Vibration 2 - Vibration ${ }_{1}$, and $\mathrm{Control}_{2}-\mathrm{Control}_{1}$ ) to assess the intrasubject reliability of $\triangle \mathrm{CBF}$ imaging and to evaluate effects attributable to stimulus order.

Once subtractions were completed, the average $\triangle \mathrm{CBF}$ volume was converted to a $t$ statistic volume by dividing each voxel by the standard error of the mean (SEM). The SEM was computed, in turn, by dividing the mean standard deviation in $\triangle \mathrm{CBF}$ for all intracerebral voxels by the square root of the number of subjects (Worsley et al., 1992).

Individual MRI images were subjected to the same averaging procedure, such that composite stereotaxic image volumes $(128 \times 128 \times$ 80 voxels, with dimensions of $1.34 \mathrm{~mm}, 1.72 \mathrm{~mm}, 1.5 \mathrm{~mm}$ in the $x ; y$; and $z$-planes, respectively) were obtained for both $t$ statistic and MRI volumes. The average MRI and $t$ statistic volumes were then merged to allow anatomical localization of the $t$ statistic peaks.

The significance of a given CBF activation was assessed by thresholding the $t$ statistic images at levels dictated by the Gaussian random field (GRAFT) model of Worsley et al. (1992). The GRAFT model predicts the likelihood of a single voxel in a three-dimensional random field exceeding a given magnitude. It incorporates the correlation among adjacent voxels and corrects for multiple comparisons when searching CBF subtraction volumes for significant activation peaks. This is achieved by replacing the voxel as the unit of volume with the "resel," a volume with dimensions equal to the image resolution in each direction $(x-$ $20 \mathrm{~mm}, y=20 \mathrm{~mm}$, and $z=8 \mathrm{~mm}$, with a $20 \mathrm{~mm}$ filter), and by considering the number of resels within a given search volume to represent the number of independent tests of the null hypothesis. The number of simultaneous tests being performed is proportional to the volume being searched, so that a directed search in a well-defined subvolume, for example, temporal lobe, will have fewer resels that an exploratory search over the whole brain.

When the GRAFT model is applied to a 200 resel volume, corresponding approximately to the gray matter volume of the human brain, a threshold of 4.0 will yield a volume-wise false positive rate of 0.12 . In other words, there is only a $12 \%$ probability that one resel in the 200 resel volume will exceed that threshold by chance. Thus, one would have to repeat the same experiment (with 8-12 subjects per experiment) eight times $(8 \times 0.12=0.96)$ before one could expect a single false positive peak to be detected. Furthermore, the probability of a given resel exceeding the threshold of $t=4.0$ by chance (e.g., uncorrected for multiple comparisons) is equivalent to $p<0.0005$. Thus, the threshold of $t=4.0$ is set conservatively. For smaller volumes, the false positive rate would be proportionately smaller and the threshold value can be relaxed.

To appraise further the reliability of identified peaks, post hoc directed searches were performed at every significant site in each individual's subtracted volume. Regional standard deviations were utilized to compute a local $t$ statistic from the mean of individual $\triangle C B F$ values. Using this method of analysis, all points displayed a $t$ value of 3.21 or greater, corresponding to $p<0.025$.

Analysis of heart rate and psychophysical ratings of stimulus intensity. Heart rates were examined in three 1 min periods before, during, and after each of the six PET scans. Rates were averaged across the two presentations of each stimulus condition, and these averages utilized 


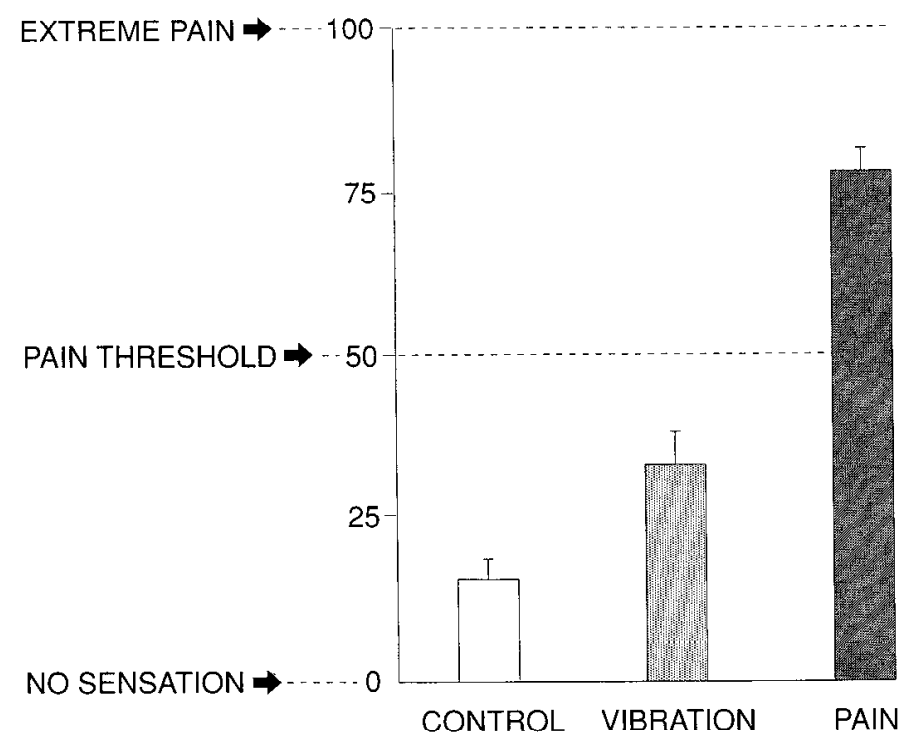

Figure 2. Mean psychophysical ratings ( \pm SEM) of stimulus intensity. Subjects rated the vibrotactile stimulus as significantly more intense than the neutral temperature $\left(34^{\circ} \mathrm{C}\right)$, but below pain threshold. The $47-$ $48^{\circ} \mathrm{C}$ heat stimulus was rated as painful and significantly more intense than the vibratory stimulus.

for subsequent analyses. A two-factor analysis of variance (ANOVA) repeated within subjects was employed to determine significant effects of time (before, during, after stimulation) and stimulus condition (Control, Vibration, Pain) on heart rate. Psychophysical ratings of stimulus intensity were analyzed by a single-factor (stimulus) ANOVA repeated within subjects.

Analysis of the relationship of heart rate and $C B F$. In order to evaluate the possible relationship between heart rate and local CBF distribution, pain-induced $\mathrm{rCBF}$ changes were tested for their correlation with heart rate changes. Each subject's heart rate during painful stimulation was expressed as a percentage of that during control stimulation, and then compared with that subject's contribution to the significant $\triangle \mathrm{CBF}$ peaks observed in the mean Pain - Control subtraction volume.

\section{Results}

Psychophysical ratings and heart rate

Subjects' ratings of stimulus intensity were dependent on the modality of stimulation presented (Fig. 2; ANOVA, $p<0.001$ ) and indicate that they were able to discriminate among the three stimuli using a single scale that included both painful and nonpainful sensations. As expected, the $47-48^{\circ} \mathrm{C}$ stimuli were rated as painful by all subjects and significantly more intense than the vibrotactile stimuli $(p<0.001)$. In turn, subjects rated the vibrotactile stimuli as significantly more intense than the $34^{\circ} \mathrm{C}$ control $(p<0.001)$.

Heart rates were also significantly influenced by testing condition (ANOVA, $p<0.04$; Fig. 3), with rates being highest during the noxious heat trials. Interestingly, however, these heart rate increases associated with the Pain condition may have been due predominately to anxiety. An analysis of these data for the 1 min period preceding each test condition revealed that heart rate was elevated before the noxious stimuli were actually applied (ANOVA comparison of "before" periods for Control, Pain, and Vibration, $p<0.03$; Fig. 3), and did not show any further significant increase during the application of the noxious heat (ANOVA contrasts, before Pain vs during Pain, $p=0.45$ ).

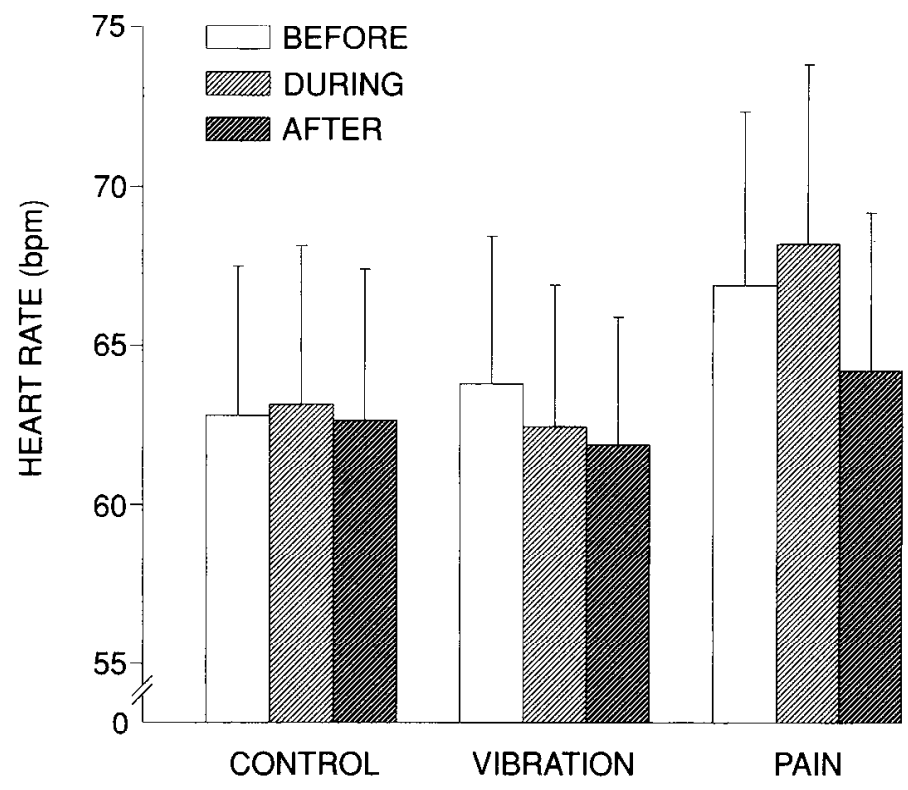

Figure 3. Mean heart rates ( \pm SEM) for nine subjects before, during, and after the $34^{\circ} \mathrm{C}$ control stimulus, the vibratory stimulus and the $47-$ $48^{\circ} \mathrm{C}$ painful heat stimulus. Heart rate "before" the Pain condition was significantly greater than that measured "before" either the Control or Vibration conditions; however, no further significant increases were observed during the application of the noxious heat.

\section{Effects of stimulus order on $C B F$ distribution}

Comparisons of the first and second presentations of the Control, Vibration, or Pain conditions showed no significant focal changes in $\mathrm{rCBF}$, indicating an absence of detectable habituation or sensitization in the current paradigm. In addition, these data indicate that intervening stimulus conditions had no discernable effect on the observed distribution of CBF. The lack of significant differences between the two Control conditions further indicates that following activated (Pain, Vibration) conditions, CBF returned to basal levels within the $15 \mathrm{~min}$ interim preceding the second Control condition. Thus, in order to reduce variability and maximize statistical power, data were averaged across the two presentations of each stimulus condition for all subsequent analyses.

\section{$C B F$ distribution during pain}

A comparison of $\mathrm{CBF}$ during Pain $\left(47-48^{\circ} \mathrm{C}\right)$ with that during Control $\left(34^{\circ} \mathrm{C}\right)$ revealed a number of cortical, subcortical, and extracerebral sites that were differentially activated during the presentation of the noxious heat stimuli (Table 1).

Cerebral cortex. As we had previously observed (Talbot et al., 1991), painful stimulation produced significant activation in regions approximating SI and SII (Table 1). SI cortex was activated contralateral to stimulation, in a region consistent with the cutaneous representation of the arm (Fig. $4 A$ ), as defined by single-unit (Mountcastle et al., 1969; Hyvärinen et al., 1980; Sinclair and Burton, 1991) and evoked-potential (Allison et al., 1989, 1991; Joseph et al., 1991) recordings in the primate. Activation observed in the region of SII cortex (near the posterior insula/parietal operculum) also was focused in the right hemisphere, contralateral to stimulation (Fig. $4 B$ ).

Painful heat stimulation also produced significant activation near the anterior portion of the insular cortex and/or the frontal 
Table 1. Pain-related foci of activation

\begin{tabular}{|c|c|c|c|c|c|}
\hline \multirow[b]{2}{*}{ Region } & \multicolumn{3}{|c|}{ Coordinates } & \multirow{2}{*}{$\begin{array}{l}\% \\
\text { Change } \\
\text { rCBF }\end{array}$} & \multirow[b]{2}{*}{$t$ Value } \\
\hline & M-L & A-P & S-I & & \\
\hline SI & 24 & -31 & 56 & 4.75 & 4.02 \\
\hline SII & 36 & -6 & 18 & 5.44 & 4.57 \\
\hline Ant. insula & 38 & 6 & 9 & 6.70 & 5.65 \\
\hline Ant. cingulate & 1 & 1 & 42 & 4.93 & 4.15 \\
\hline SMA (inferior) & 1 & -4 & 54 & 5.95 & 5.00 \\
\hline SMA (superior) & 5 & -6 & 66 & 4.78 & 4.02 \\
\hline Thalamus & 11 & -19 & -3 & 5.36 & 4.53 \\
\hline Putamen (ipsi.) & -25 & 1 & -8 & 5.46 & 4.57 \\
\hline Putamen (ipsi.) & -23 & -7 & 6 & 4.99 & 4.23 \\
\hline $\begin{array}{c}\text { Extracerebral } \\
\text { (temporal) }\end{array}$ & 75 & 15 & -3 & 5.03 & 4.23 \\
\hline $\begin{array}{c}\text { Extracerebral } \\
\text { (temporal) }\end{array}$ & 68 & 17 & 8 & 6.01 & 5.05 \\
\hline $\begin{array}{l}\text { Extracerebral } \\
\text { (ipsi. temporal) }\end{array}$ & -71 & 22 & -3 & 6.03 & 5.09 \\
\hline $\begin{array}{l}\text { Extracerebral } \\
\quad \text { (ipsi. temporal) }\end{array}$ & -70 & 15 & -13 & 5.78 & 4.87 \\
\hline $\begin{array}{l}\text { Extracerebral } \\
\text { (frontal) }\end{array}$ & 34 & 53 & 30 & 4.77 & 4.02 \\
\hline Post cingulate & 1 & -50 & 29 & -6.08 & -5.14 \\
\hline Orbital gyrus & 20 & 67 & -11 & -4.70 & $-3.99 a$ \\
\hline Ant. insula (ipsi.) & -31 & 5 & 5 & 4.43 & $3.72^{a}$ \\
\hline
\end{tabular}

Coordinates of peak activation are expressed in millimeters. M-L, medial-lateral relative to midline (positive $=$ right); $\mathrm{A}-\mathrm{P}$, anterior-posterior relative to anterior commissure (positive $=$ anterior); $\mathrm{S}$ - $\mathrm{I}$, superior-inferior relative to commissural line (positive $=$ superior). Negative $t$ values indicate that blood flow was less during the Pain condition than during the Control condition.

"Below the threshold of statistical significance.

operculum (Table 1, Fig. 4C). A trend toward activation $(i=$ 3.72) was observed in the ipsilateral anterior insular region, suggesting that this area may be activated bilaterally (Table 1, Fig. 4().

Three pain-related regions of activation were also observed along the medial wall of the right frontal cortex, contralateral to stimulation. The most inferior of these medial foci was in area 24 of the anterior cingulate cortex (Table 1, Fig. 5A), a region previously observed to be activated in the human during painful stimulation (Jones et al., 1991; Talbot et al., 1991). Superior to the anterior cingulate activation, two foci were detected within the supplementary motor area (SMA). Both SMA foci occurred within area 6 of the superior frontal gyrus, with one being situated superior to the other (Table 1, Fig. $5 A$ ).

Two cortical regions demonstrated a decrease in rCBF during the Pain condition, compared to the Control (negative $t$ values of Table 1). One of these foci was located medially in the posterior cingulate gyrus in a position approximating area 31 (Fig. $6 D$ ). The other focus was located in area 10 near the anterior tip of the orbital gyrus (Fig. $6 \mathrm{~A}$ ). Both of these pain-related sites of decreased rCBF were situated in the right hemisphere, contralateral to the stimulated forearm (Fig. 6A).

Subcortical regions. Pain-related increases in $\mathrm{rCBF}$ were observed in the area of basal thalamus (Table 1, Fig. $5 B$ ), contralateral to the stimulated arm. Activation of any or all of a number of adjacent thalamic nuclei, including VP, Sm, and Pf, could have contributed to this focus, since the PET imaging technique is unable to distinguish among structures of such close prox-
Table 2. Vibration-related foci of activation

\begin{tabular}{lrrrrr} 
& \multicolumn{3}{c}{ Coordinates } & \multicolumn{2}{c}{$\%$} \\
\cline { 2 - 4 } Region & M-L & A-P & S-I & rCBF & $t$ Value \\
\hline SI & 28 & -31 & 57 & 6.02 & 5.21 \\
SII & 42 & -21 & 15 & 6.68 & 5.78 \\
SII (ipsi.) & -55 & -26 & 21 & 4.65 & 4.04 \\
Post. insula & 38 & -13 & -5 & 5.10 & 4.39 \\
Post. insula (ipsi.) & -32 & -7 & -8 & 4.70 & 4.04 \\
Middle frontal gyrus & 44 & 32 & 22 & -5.21 & -4.51 \\
Middle frontal gyrus & 44 & 20 & 31 & -4.84 & -4.21 \\
Orbital gyrus & 20 & 65 & -11 & -4.92 & -4.25 \\
SMA & 5 & -19 & 47 & 4.31 & $3.69^{\circ}$ \\
Ant. cing. & 3 & 3 & 39 & 4.52 & $3.38^{\circ}$ \\
Thalamus & 11 & -23 & -3 & 3.42 & $2.95^{\circ}$
\end{tabular}

Coordinates of peak activation are expressed in millimeters. M-L, A-P, and S-I are defined in Table 1. Negative $t$ values indicate that blood flow was less during the Vibration condition than during the Control condition.

"Below the threshold of statistical significance.

imity. In the ipsilateral hemisphere, painful stimulation produced a significant increase in $\mathrm{rCBF}$ only in the region of the putamen (Table 1, Fig. 4C)

Extracerebral regions. In addition to the intracerebral changes in $\mathrm{rCBF}$, significant increases in extracerebral blood flow were detected on both sides of the head when the Pain condition was compared to the Control (Table 1, Fig. 4C). These extracerebral increases in rCBF occurred in areas adjacent to the temporalis muscle and superficial temporal artery.

Relationship between $C B F$ and heart rate changes. None of the intracerebral blood flow changes related to painful stimulation were significantly correlated with either heart rate increases or extracerebral blood flow changes. In contrast, extracerebral increases in blood flow, ipsilateral to stimulation, were strongly correlated with increases in heart rate that occurred during painful stimulation $(r=0.91, p<0.001)$. Contralateral extracerebral blood flow changes, however, werc not significantly related to changes in heart rate $(r=0.44, p=0.232)$.

\section{$C B F$ distribution related to vibration}

A comparison of CBF during Vibration with that during Control stimulation revealed significant peaks at several loci, as detailed in Table 2.

Cerebral cortex. As observed for pain, vibrotactile stimulation produced significant increases in $\mathrm{rCBF}$ within the areas of SI and SII (Table 2, Fig. 4A,B). The stereotaxic coordinates of the Vibration-related SI focus were indistinguishable from those associated with the SI activation observed in the Pain condition. In contrast, the Vibration-related SII focus, centered deep within the lateral sulcus near the posterior insula, was localized somewhat posterior to that observed during the Pain condition (Fig. $4 C$ ). Additional sites of activation observed during the Vibration condition were an ipsilateral region in the vicinity of SII (Table 2, Fig. $4 B$ ), as well as a bilateral activation within the insular cortex, anterior to SII (Table 2, Fig. 4C).

No statistically significant changes in rCBF related to Vibration were detected in the anterior cingulate gyrus or SMA. Nevertheless, trends toward significant activation were identified in both regions (with $t$ values of 3.38 and 3.69, respectively; Table 


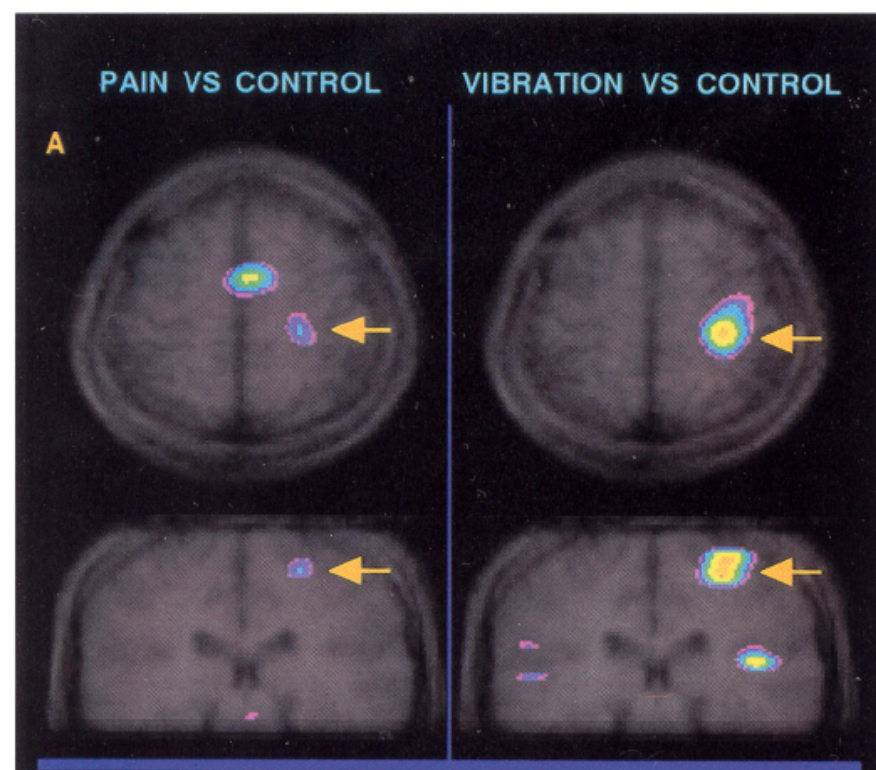

2), suggesting that those areas that showed increases in $\mathrm{rCBF}$ during Pain may also be activated to some extent during Vibration.

Although most differences between the Vibration and Control conditions involved increases in rCBF during Vibration, two foci within the contralateral middle frontal gyrus showed $d e$ creased $\mathrm{rCBF}$ during Vibration relative to Control (Table 2, Fig. $6 B, C$ ). In addition, a significant vibration-related decrease in $\mathrm{rCBF}$ was also observed in the anterior tip of the contralateral orbital gyrus (area 10), an area that exhibited a similar decrease in $\mathrm{rCBF}$ during the Pain condition (Fig. 6A).

Subcortical regions. No statistically significant $\mathrm{rCBF}$ changes were observed in the subcortical structures examined, when Vibration was compared to Control. Activation within thalamus fell far short of meeting our statistical criteria for reliability $(t$ $=2.95$, Table 2).

\section{Comparison of pain- and vibration-induced changes in $r C B F$}

Pain and Vibration conditions produced similar changes in $\mathrm{rCBF}$ in several areas of the cerebral cortex. Increases in rCBF produced by Pain overlapped extensively with those produced by Vibration within SI, and to a lesser extent in SII. In addition, as indicated above, decreases in $\mathrm{rCBF}$ were also noted in both Pain and Vibration conditions within the same area of the orbitofrontal gyrus, contralateral to the stimulated arm.

Relative to the control condition, significant increases in rCBF during the Pain condition, but not during the Vibration condition, were noted in a number of cortical and subcortical areas-including anterior cingulate cortex, SMA, anterior insula, and basal thalamus-all contralateral to the stimulated arm. Nevertheless, a direct statistical comparison of Pain versus Vibration revealed that the only intracerebral region showing significantly increased rCBF during Pain, relative to either Control or Vibration, was the anterior portion of the contralateral insular cortex (Table 3, Fig. 5C). Two of the extracerebral activation sites also showed significantly greater $\mathrm{rCBF}$ during Pain than during Vibration (Table 3, Fig. $4 C$ ). In contrast, no site showed reduced $\mathrm{rCBF}$ during Pain relative to Vibration.

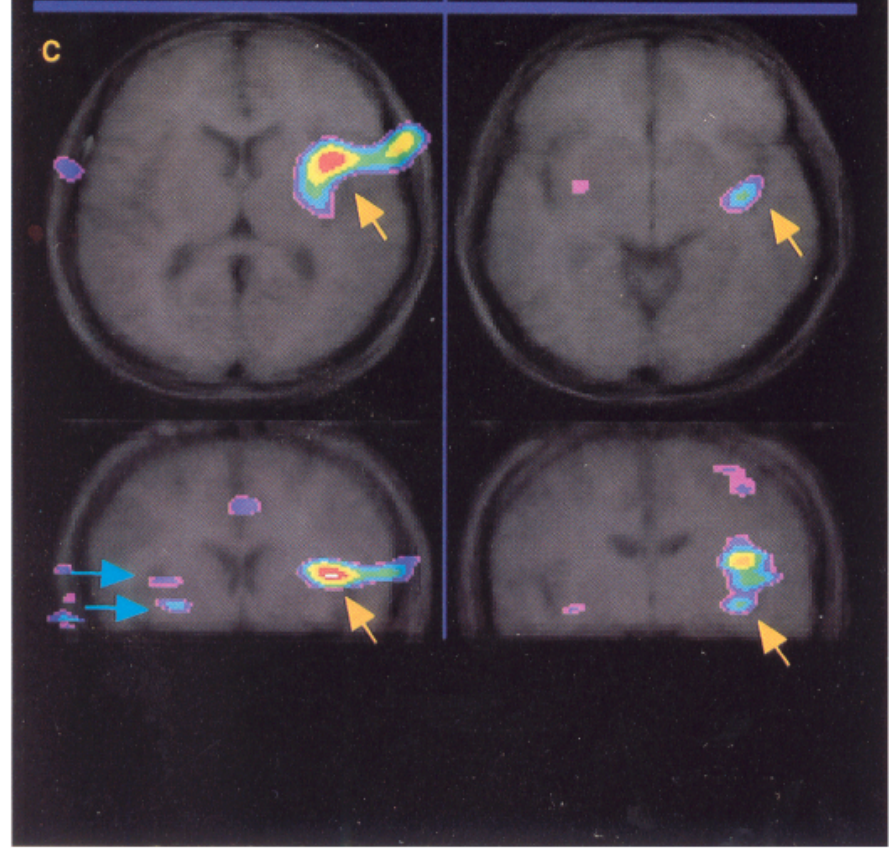

\section{Discussion}

The present results show that, in normal human subjects, cutaneous heat pain produces contralateral activation in a number of cortical and subcortical sites, including SI, SII, anterior cingulate, anterior insula, SMA, and thalamus. In addition, our data suggest that this pattern of pain-related activation is distinct

\section{$\leftarrow$}

Figure 4. Merged PET-MRI horizontal and coronal slices averaged across nine subjects, showing the distribution of cerebral blood flow during painful heat and vibratory stimulation, relative to the $34^{\circ} \mathrm{C}$ control stimulus. The range of $t$ values for PET data is coded by color (see color bar, Fig. 5). A, Both painful (left) and vibrotactile (right) stimulation produced significant activation within contralateral SI cortex (denoted by arrows). $B$, Both painful and vibrotactile stimulation produced contralateral activation within SII and adjacent regions (denoted by arrows). $C$, Both painful and vibrotactile stimulation produced activation within the insula. However, pain-induced insular activation occurred anterior and superior to that produced by vibrotactile stimulation. Painful stimulation also produced activation on the border of the ipsilateral claustrum and putamen (blue arrows). The coronal sections also show that bilateral extracerebral increases in blood flow were produced by painful, but not vibrotactile, stimulation. The averaged MRI data reflect the underlying anatomical variability between subjects, and hence are not as detailed as individual images. 


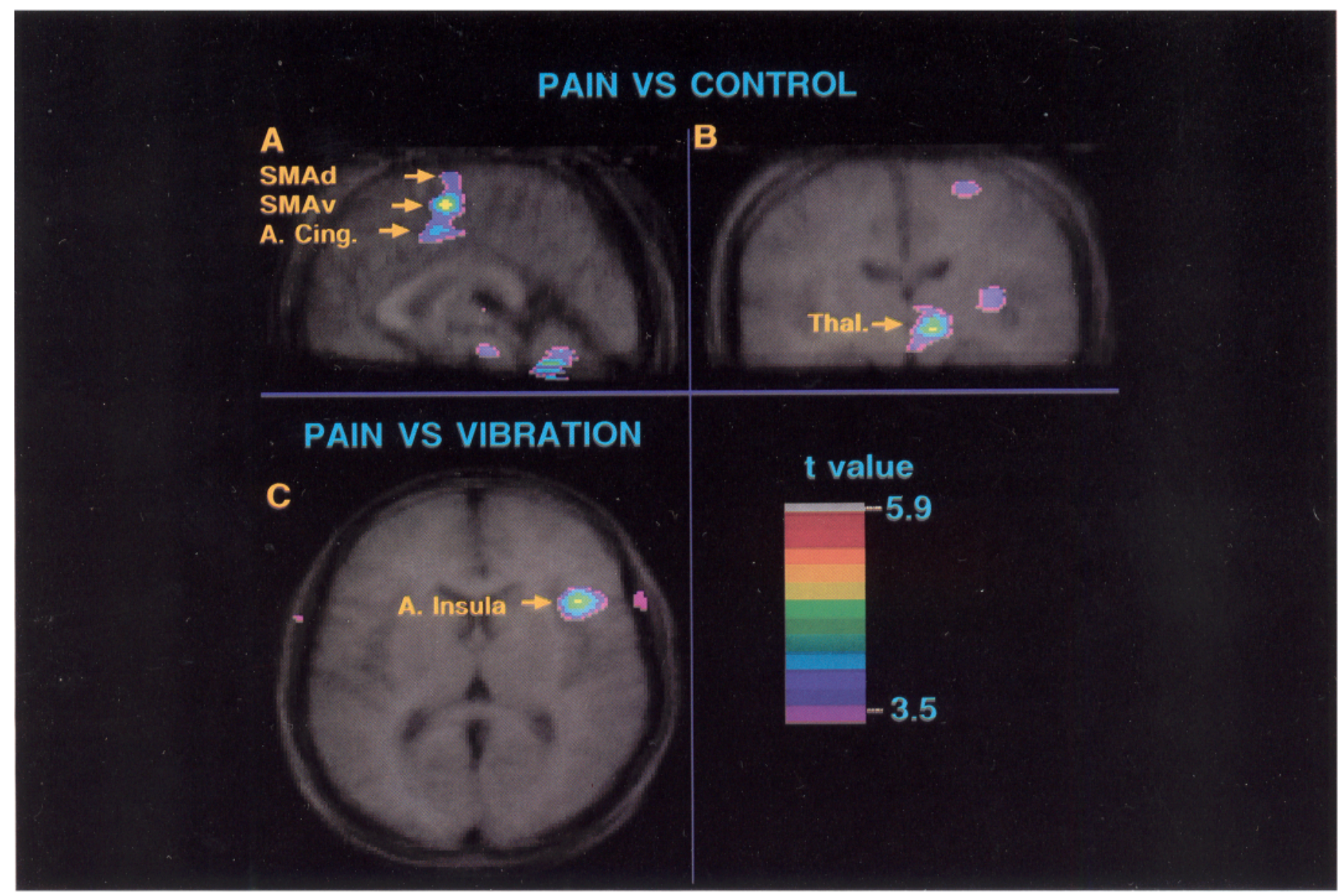

Figure 5. A, Painful stimulation produced significant blood flow changes along the medial wall of the contralateral hemisphere. These loci included area 24 of the anterior cingulate cortex ( $A$. Cing.), and inferior and superior regions of the supplementary motor cortex (SMAv, SMAd, respectively). $B$, Painful stimulation produced significant activation within the contralateral thalamus (Thal.). $C$, A direct comparison of pain and vibrotactile stimulation revealed significantly greater activation during pain than during vibration in the anterior portion of the contralateral insular cortex and in a contralateral extracerebral region.

from that produced by innocuous cutaneous stimuli. Painful stimuli produced significantly greater activation of the anterior insular cortex than did vibrotactile stimulation. In contrast, vibrotactile stimulation led to a bilateral activation of the posterior insula that was not observed for painful stimulation. Vibrotactile stimulation did activate regions of SI and SII, but did not produce statistically significant changes in rCBF in the other sites activated by pain. These findings indicate that the painrelated activation of SI and SII observed in our previous study (Talbot et al., 1991) and the thalamic activation observed by Jones et al. (1991) are reliable, reproducible phenomena. Further, these results confirm that multiple cerebral cortical regions are involved in the pain experience.

\section{Comparison with previous studies}

In addition to confirming the areas of pain-related activation observed in Talbot et al. (1991) and Jones et al. (1991), the present results revealed additional cortical areas (i.e., SMA and anterior insular cortex) that were activated during the presentation of noxious cutaneous heat. There are several possible reasons for the increased number of regions showing significant activation. Technical differences, such as a larger number of subjects (nine vs eight) and a higher average dose of radioactive tracer ( 39.4 vs $30.8 \mathrm{mCi}$ ) reaching the brain, may have led to an increased sensitivity in the present study compared to our previous report (Talbot et al., 1991).

At least three differences in study design may also have contributed to the increased number of activation sites observed in the present study. First, the present study utilized a neutral

\section{Table 3. Foci of activation related to comparison of pain and} vibration

\begin{tabular}{lccccc} 
& \multicolumn{3}{c}{ Coordinates } & \multicolumn{3}{l}{$\%$} & \multicolumn{2}{l}{$\begin{array}{l}\text { Change } \\
\text { Region }\end{array}$} & M-L & A-P & S-I & & rCBF & $t$ Value \\
\cline { 2 - 5 } $\begin{array}{l}\text { Ant. insula } \\
\begin{array}{c}\text { Extracerebral } \\
\text { (ipsi. temporal) }\end{array}\end{array}$ & 42 & 15 & 9 & 5.17 & 4.69 \\
$\begin{array}{c}\text { Extracerebral } \\
\text { (temporal) }\end{array}$ & 68 & 13 & -11 & 5.44 & 4.96
\end{tabular}

Coordinates of peak activation are expressed in millimeters. M-L, A-P, and S-I are defined in Table 1 . 


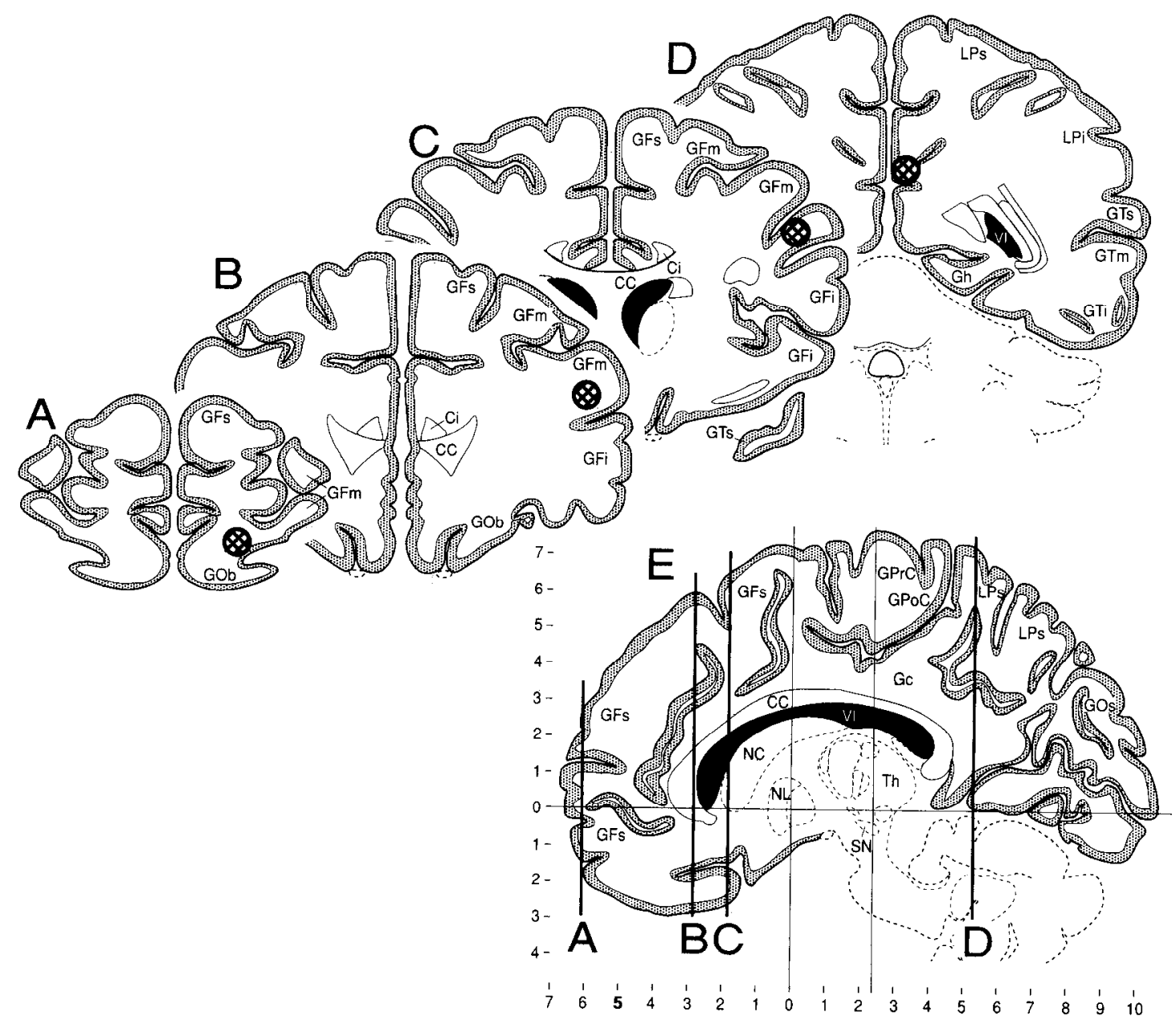

Figure 6. Regions in which painful or vibrotactile stimulation produced less activation than did the control stimulation. $A$, Both painful and vibrotactile stimulation produced less activation than control stimulation in the contralateral orbital gyrus of the prefrontal cortex (area 10). Although stereotaxic coordinates placed these activation sites near the border of the brain, MRI data confirmed that this activation is within the brain. $B$ and $C$, Vibrotactile stimulation produced significantly less activation than control stimulation at two loci within the middle frontal gyrus. $D$, Painful stimulation produced significantly less activation than control stimulation in the posterior cingulate cortex. See Figure 1 for abbreviations (after Talairach and Tournoux, 1988).

$\left(34^{\circ} \mathrm{C}\right)$ control, whereas our previous study and that of Jones et al. (1991) used a warm $\left(41-42^{\circ} \mathrm{C}\right)$ control; thus, the present activation might reflect a combined representation of pain and warmth. However, warm fiber activity is suppressed by noxious heat, so that with repeated heat pulses, the warm fiber input probably contributed little to the observed cerebral activation (Duclaux and Kenshalo, 1980). Second, a thermally neutral control stimulus would undoubtedly produce less activation than a maximally warm control stimulus; thus, subtractions between neutral and painful stimuli would be predicted to yield a greater magnitude of differences than subtractions between warm and painful stimuli. Finally, the preliminary practice sessions of the present experiment may not have been as effective as those of our previous study in reducing pain-related anxiety, since this study's subjects showed increased heart rates before and during the noxious heat conditions, while those in our previous study did not. Although several PET studies indicate that high levels of anxiety are not associated with any specific regional increases in neuronal activation (Reiman et al., 1989; Drevets et al., 1992), it is possible that high levels of anxiety may modulate or enhance pain-evoked neural responses, particularly in brain regions involved in affective responses to pain.

\section{Activation in SI cortex}

Both noxious heat and vibrotactile stimuli led to an increased blood flow in the contralateral postcentral gyrus in a region consistent with the arm representation of the primary somatosensory cortex. The vibrotactile-induced activation of SI is not surprising, in that other blood-flow studies in humans and monkeys have consistently observed such activation (Fox et al., 1987; Meyer et al., 1991; Perlmutter et al., 1991; Seitz and Roland, 1993). These PET results are also consistent with findings of single-unit studies in monkeys, which show that vibration induces highly focal increases in neuronal activity in SI cortex (Mountcastle et al., 1969; Hyvärinen et al., 1980).

Our findings of SI activation during painful stimulation were less predictable. Early human lesion and stimulation data had suggested a minimal role of SI cortex in pain processing. Head and Holmes (1911) observed that pain perception remained generally intact despite widespread injury to the cerebral cortex, and White and Sweet (1969) reported that SI lesions provide only temporary relief from chronic pain. Similarly, Penfield and Boldrey (1937) also discounted the possible role of the SI cortex in the perception of pain based on the paucity of painful sen- 
sations produced by electrical stimulation during neurosurgical procedures. More recently, however, Young and Bloom (1983) have reported that some patients with epileptic foci involving SI cortex do experience pain during seizures.

Although we had previously observed pain-induced activation of SI (Talbot et al., 1991), other groups have not observed significant increases in rCBF in SI cortex (Jones et al., 1991; Apkarian et al., 1992). One factor that may have contributed to the absence of SI and SII activation in the Jones et al. study (1991) is that their heat stimulus $\left(46.4^{\circ} \mathrm{C}\right)$ only approximated the theshold for nociceptive activity in primary somatosensory neurons (Kenshalo et al., 1988), and thus may not have been sufficiently intense to produce a statistically detectable blood flow change. In addition, their use of only one stimulation site would not have evoked the spatial summation of pain intensity (Price et al., 1989; Douglass et al., 1992) that has been observed with multiple stimulation sites, as employed in our two studies.

The present results and those of our previous study (Talbot et al., 1991) indicate that, despite the difficulty of identifying pain-related activity in the human SI cortex with lesion and stimulation methods, a contralateral representation of pain-related activity clearly coexists with the tactile representation. Single-unit investigations in monkeys support these human data. Kenshalo and co-workers have identified a small population of SI nociceptive neurons that encode the intensity of noxious thermal stimulation (Kenshalo and Isenesee, 1983; Kenshalo et al., 1988; Chudler et al., 1990); the responses of these neurons correlate with both the monkey's ability to detect changes in noxious stimulus intensity (Kenshalo et al., 1988) and with humans' ratings of pain intensity evoked by identical noxious stimuli (Chudler et al., 1990). Since the majority of these SI nociceptive neurons have convergent or wide-dynamic-range (i.e., respond to both painful and nonpainful stimuli in a graded fashion) response properties (Kenshalo et al., 1988; Chudler et al., 1990), it is likely that a significant proportion of neurons contributing to the pain-induced activation in the present study also contribute to the vibrotactile activation. These findings, along with additional evidence that bilateral ablation of SI in monkeys disrupts their ability to discriminate intensities of noxious heat (Kenshalo et al., 1991), suggest that this region is involved in the sensory-discriminative component of pain perception. However, given the equivocal stimulation and lesion results in humans, it appears that although this region may contribute to pain perception, other regions must necessarily be activated for the full experience of pain.

\section{Activation of SII and posterior insula}

Noxious heat and vibrotactile stimulation each produced a significant increase in rCBF near the contralateral inferior face of the parietal operculum, in the region defined in the monkey as SII (Roberts and Akert, 1963; Friedman and Murray, 1986), and the Vibration condition activated a similar region ipsilateral to the site of peripheral stimulation. These results confirm previous findings of increased $\mathrm{ICBF}$ in human SII related to both noxious heat (Talbot et al., 1991) and vibrotactile stimulation (Fox et al., 1987; Seitz and Roland, 1992).

The present study also revealed a bilateral activation within the posterior insular cortex, probably in the granular subdivision (Ig), during vibrotactile but not noxious heat stimulation. Anatomical data in monkeys showing a projection to Ig from ventroposterior inferior (VPI) thalamus (Friedman and Murray, 1986), a nucleus with strong pacinian input (Herron and Dykes,
1987), is consistent with vibrotactile activation in the posterior insula.

The finding that vibrotactile stimulation produced bilateral activation in the region of SII and Ig is consistent with singleunit recordings in rhesus monkeys. Although receptive fields of monkey SII neurons are mostly contralateral, those in the neighboring $7 \mathrm{~b}$ region are generally bilateral (Robinson and Burton, $1980 \mathrm{a}, \mathrm{b})$. Thus, the present activation may include contributions from both of these areas. Similarly, receptive fields of Ig neurons are generally large and bilateral (Robinson and Burton, 1980 b). Only a few nociceptive neurons have been identified in the region of SII/posterior insula in the monkey (Robinson and Burton, 1980c; Dong et al., 1989) and most of these had bilateral receptive fields. Nevertheless, our finding of a preferentially contralateral representation of pain in SII is supported by the observation of Greenspan and Winfield (1992) that a tumor compromising SII resulted in higher pain thresholds on the hand contralateral to the tumor than on the ipsilateral hand. This psychophysical difference was reduced after the tumor was removed, suggesting a predominantly contralateral representation of pain in SII.

The exact role that SII cortex plays in the processing of tactile and pain information is not certain. Data in rhesus monkeys showing that SII somatosensory responsiveness is dependent on an intact SI cortex (Pons et al., 1992), as well as observations in humans and monkeys that lesions of SII lead to deficits in both tactile and pain discrimination (Murray and Mishkin, 1984; Greenspan and Winfield, 1992), suggest that SII and SI may function together to process discriminative aspects of somatosensation. However, since lesions of SI only temporarily alleviate chronic pain (White and Sweet, 1969) and since SII receives direct thalamic input sufficient to transmit nociceptive information (Friedman and Murray, 1986), SII may not necessarily be dependent on serial transmission of information from SI for the processing of pain.

\section{Anterior insular cortex}

Noxious heat, but not vibrotactile, stimulation was found to activate a region of the contralateral anterior insular cortex, probably in the disgranular portion (Id). This was the only brain region in which we observed significantly greater blood flow during pain than during vibrotactile stimulation (see Table 3 ). No study has yet shown nociceptive neuronal activity in Id; nevertheless, this region has connections with a number of cortical areas implicated in nociception, such as SI, SII, and area 24 of the anterior cingulate cortex (Mufson and Mesulam, 1982; Fricdman ct al., 1986). Similarly, it receives input from the posterior portion of the ventromedial thalamic nucleus (Friedman and Murray, 1986), an area recently shown to receive a strong projection from lamina I of the spinal cord (Craig, 1992) and to contain a high concentration of nociceptive neurons (Bushnell and Craig, 1993).

Several lines of evidence suggest that the pain-related activation in anterior insula may reflect circuitry involved in the affective and reactive components of pain. First, Id has been shown to project to various limbic structures, such as the amygdaloid complex and perirhinal cortex (Friedman et al., 1986). Second, although stimulation in the anterior insular cortex produces predominantly visceral sensations, it also evokes unusual somatic sensations, movements, and sometimes a sense of fear (Penfield and Rasmussen, 1955; Feindel, 1961; Pentield and Faulk, 1984). Finally, Berthier et al. (1988) reported one patient 
with an anterior insular lesion who showed inappropriate emotional responses to painful stimuli or to threatening gestures. Insular links with the limbic system may be essential for integrating ongoing pain with memory, allowing full appreciation and evaluation of the meaningfulness of the stimulus in light of previous experience. Such a process would be a key component of pain affect (Price, 1988).

\section{Anterior cingulate gyrus}

Area 24 of the anterior cingulate cortex, contralateral to the stimulated arm, was significantly activated by noxious heat stimuli in the present study. This result confirms findings of previous blood flow studies (Jones et al., 1991; Talbot et al., 1991), and shows that this activation is not lateralized to one hemisphere.

In addition to the consistent activation of area 24 in bloodflow studies, several other lines of evidence implicate this region in pain processing. Area 24 receives input from thalamic nuclei containing nociceptive neurons, such as (Pf), Sm, and the base of VP (Craig et al., 1982; Vogt et al., 1987, 1993; Musil and Olson, 1988; Yasui et al., 1988). Surgical lesions of area 24 in humans have been shown to relieve chronic pain (Foltz and Lowell, 1962; Hurt and Ballantine, 1973), and lesions to the cingulum bundle in rats reduce nociceptive behaviors elicited by subcutaneous injection of formalin (Vaccarino and Melzack, 1989). More recently, nociceptive neurons have been identified in anterior cingulate area 24 of rabbits (Sikes and Vogt, 1992).

The anterior cingulate cortex is, however, by no means exclusively involved in nociception. PET studies in humans indicate that portions of the anterior cingulate may be involved in visual attention (Pardo et al., 1990; Corbetta et al., 1991), while animal behavior data show its involvement in avoidance learning (Thomas and Slotnick, 1963; Gabriel et al., 1991). Area 24 of monkey has been shown to contain movement-related foci (Luppino et al., 1991; Shima et al., 1991) and to have corticospinal projections (Hutchins et al., 1988). The anterior cingulate cortex may also be involved in autonomic responses to external stimuli. Stimulation in this region produces changes in respiration and cardiovascular function in animals and man (Lofving, 1961; Hoff et al., 1963), and single neurons with a discharge frequency related to cardiac or respiratory cycle have been identified in cats (Frysinger and Harper, 1986). Such data suggest a broad role of area 24 in modulating behavioral reactions to external stimuli. The consistent activation of this region in blood-flow studies involving painful stimulation may reflect the importance of nociceptive input in this modulatory process.

\section{Supplemental motor area}

Noxious heat, but not vibrotactile, stimuli produced significant activation in the region of SMA in the frontal cortex. This region is thought to be involved in motor control (see Wise and Strick, 1984, for review). Single-unit studies in monkeys show activity of SMA neurons during a waiting period in preparation for movement (Kurata and Wise, 1988; Dao-fen et al., 1991). Further, electrical stimulation of SMA in humans frequently produces an urge to move or evokes an actual movement (Penfield and Rasmussen, 1955). Finally, human blood-flow studies using PET have shown activation of SMA during tasks involving the planning and execution of movement (Roland et al., 1980a,b; Deiber et al., 1991). Thus, the SMA activation of the present study may indicate a preparation and readiness to move the stimulated arm in the avoidance of danger, despite our subjects' denial of any urge to withdraw from the noxious stimuli.

\section{Thalamus}

In the present study and in the study by Jones et al. (1991), there was a significant blood-flow increase in the thalamus during noxious heat stimulation. In contrast, we did not observe a significant activation of thalamus during vibrotactile stimulation. These findings are somewhat surprising, in that vibrotactile information is known to be processed in the thalamus (Herron and Dykes, 1987; Ghosh et al., 1992). Nonetheless, other investigators measuring cerebral blood flow have also failed to detect vibrotactile-induced increases in the thalamus (Fox et al., 1988; Seitz and Roland, 1993), although combinations of sensory and motor tasks do produce reliable activation (Seitz ct al., 1991).

At least two factors could contribute to these findings of significant thalamic activation during noxious heat but not vibrotactile stimulation. First, although noxious tactile stimuli activate only a small percentage of neurons recorded in the primate somatosensory (VP) thalamus (Perl and Whitlock, 1961; Kenshalo et al., 1980; Casey and Morrow, 1983; Lenz et al., 1990; Bushnell et al., 1993; Tremblay et al., 1993), these stimuli are quite effective in activating neurons distributed throughout a larger area within the thalamus, including the ventromedial posterior nucleus, $\mathrm{Pf}, \mathrm{Sm}$, centralis medialis, and the posterior nucleus (Casey, 1966; Dong et al., 1978; Andersen and Dafny, 1983; Dostrovsky and Guilbaud, 1988, 1990; Bushnell and Duncan, 1989; Miletic and Cottield, 1989; Bushnell and Craig, 1993). Second, medial thalamic nociceptive neurons have larger receptive fields than thalamic low-threshold neurons (Cascy, 1966; Dong et al., 1978; Andersen and Dafny, 1983; Dostrovsky and Cuilhaud, 1988, 1990; Bushnell and Duncan, 1989; Miletic and Coffield, 1989), so a larger proportion of these neurons would be activated by a noxious stimulus on the arm. The effect of larger receptive field size on metabolic activity is seen in 2-deoxyglucose studies of the rat spinal cord, in which a noxious heat stimulus to the foot activates five segments of the lumbar spinal cord, while vigorous brushing activates only one segment (Coghill et al., 1991, 1993). Thus, the more widespread activation of nociceptive cells within a larger number of thalamic nuclei would produce a substantial target of pain-related activity readily detectable by $P E T$.

\section{Areas with decreased blood flow during pain or vibration}

In addition to the CBF increases observed during pain and/or vibration relative to the ncutral control temperature, we observed a small number of decreases in CBF during the experimental conditions. During pain there was a decrease in CBF in the posterior cingulate cortex, and during vibration in the middle frontal gyrus. For both conditions, there was a decrease in CBF to the orbital frontal gyrus (area 10). In a study comparing vibration with a rest condition, Seitz and Roland (1993) reported a number of regional decreases in $\mathrm{CBF}$, suggesting that they reflect a shift away from information processed in these structures.

The functional significance of $\mathrm{rCBF}$ decreases in the present study is less clear since an active $\left(34^{\circ} \mathrm{C}\right)$ control condition, rather than a nonstimulated baseline condition, was employed. Thus, decreased rCBF may indicate areas that exhibit increased activation during the control condition, relative to the experimental condition, reflecting some unexpected cognitive or sen- 
sory differences across the subtraction pair. Conversely, these regional decreases in $\mathrm{CBF}$ may indicate a real reduction in activity (from the normal baseline levels of processing within these structures) consequent to the specific demands of the experimental condition.

The neuronal mechanisms underlying decreases in $\mathrm{rCBF}$ are not well understood, especially at the level of the cerebral cortex. A reduction in $\mathrm{rCBF}$ cannot bc interpreted uncquivocally as a local inhibitory process, since the release of inhibitory neurotransmitters is considered an energy-demanding event likely to evoke increases in rCBF (Sokoloff, 1991). However, in a cortical area rich with intrinsic neurons, this direct metabolic demand associated with the release of an inhibitory neurotransmitter might be inconsequential, compared to a larger reduction in the aclivity of the local modulatory processes. An equally plausible explanation for a local decrease in CBF is a diminished input to the region that results from active inhibition occurring at a preceding level of processing. In addition, reductions in $\mathrm{rCBF}$ might result from the passive shunting of blood to nearby activated areas. Thus, a clear explanation for the observed decreases in rCBF awaits a better understanding of the relationship between the blood flow and metabolic demands of the different components within the local circuitry of the regions involved.

\section{Extracerebral blood flow and heart rate changes}

Pain but not Vibration produced bilateral increases in extracerebral blood flow as well as increases in heart rate. Several lines of evidence suggest that anxiety may have played an important role in modulating these two dependent measures. Similar extracerebral changes have been observed during cholecystokinin-induced anxiety (Benkelfat et al., 1991) and during anxiety produced by the anticipation of pain (Reiman et al., 1989; Drevets et al., 1992). These extracerebral changes could reflect increased perfusion of the temporalis muscles if the subjects were clenching their jaws, or could represent increased flow in the superficial temporal artery that might result from the elevated heart rates observed during the Pain condition. The significant correlation observed between the magnitude of CBF increases in some of the extracerebral foci and changes in heart rate lends support to their possible interactions.

The fact that heart rate was elevated before the painful stimuli were actually administered further suggests a role of anxiety in producing these changes. This apparent anticipatory anxiety was observed despite counterbalancing the stimulus order and maintaining a single-blind paradigm design. Since only three stimulus conditions were utilized across the six scans, some subjects may have anticipated the prescntation of the painful condition after completion of Control and Vibration scans.

\section{Significance of multiple sites of nociceptive processing}

The multiple brain regions activated by noxious stimulation reflect the complex nature of the pain experience, which involves sensory-discriminative and affective components, and may include fear and anxiety, as well as autonomic and motoric reactions. Anatomical connectivity suggests that certain activated regions, such as anterior insular cortex, may be involved in pain affect by integrating somatosensory information with memory. Other regions, such as the SMA and anterior cingulate cortex, may involve modulation of motoric and/or autonomic reactions to pain. Finally, certain areas, such as SI and SII cortices, may contribute primarily to spatial, temporal, and intensity discrimination of painful stimuli. Although each region mentioned above may be preferentially involved with some specific task, the number of different brain regions activated by painful stimulation and high degree of connectivity between these areas strongly suggest that pain is processed by complex cortical and subcortical networks.

A distributed pain system would explain the difficulty of eliciting painful sensations by cortical stimulation, since simultaneous activation of several regions could be necessary for pain. Similarly, a distributed pain system would explain why discrete cortical lesions seldom lead to a complete reduction in pain, but may alter certain aspects of the pain experience or behavioral reactions to pain (Foltz and Lowell, 1962; Hurt and Ballantine, 1973; Berthier et al., 1988; Stein et al., 1989; Kenshalo et al., 1991; Talbot et al., 1993), and why chronic pain may initially be alleviated by lesions at different levels of the neuraxis, but usually returns after a period of months (White and Sweet, 1969; Vierck and I.uck, 1979; Vierck et al., 1990). This resilience of chronic pain may involve a plasticity in pain pathways, whereby functions usually performed by one region are taken over by another. Such redundancy and resiliency are of obvious evolutionary value, since nociception is essential for survival (Melzack, 1973). Further studies in which the perception of and behavioral reactions to noxious stimuli are precisely measured and correlated with regional cerebral activation will help define the role of various brain regions in the experience of pain.

\section{References}

Allison T, McCarthy G, Wood CC, Darcey TM, Spencer DD, Williamson PD (1989) Human cortical potentials evoked by stimulation of the median nerve. I. Cytoarchitectonic areas generating short-latency activity. J Neurophysiol 62:694-710.

Allison T, Wood CC, McCarthy G, Spencer DD (1991) Cortical somatosensory evoked potentials. II. Effects of excision of somatosensory or motor cortex in humans and monkeys. J Neurophysiol 66: 64-82.

Andersen E, Dafny N (1983) Dorsal raphe stimulation reduces responses of parafascicular neurons to noxious stimulation. Pain 15: 323-331.

Apkarian AV, Hodge CJ (1989) Primate spinothalamic pathways: III. Thalamic terminations of the dorsolateral and ventral spinothalamic pathways. J Comp Neurol 288:493-511.

Apkarian AV, Stea RA, Manglos SH, S7everenyi NM, King RB, Thomas FD (1992) Persistent pain inhibits contralateral somatosensory cortical activity in humans. Neurosci Lett 140:141-147.

Benkelfat C, Bradwejn J, Meyer E, Ellenbogen M, Milot S, Gjedde A, Evans AC (1993) Neuroanatomical correlates of CCK4-induced panic attacks in normal volunteers. Arch Gen Psychiatry, in press.

Berthier M, Starkstein S, Leiguarda R (1988) Asymbolia for pain: a sensory-limbic disconnection syndrome. Ann Neurol 24:41-49.

Bowsher D (1957) Termination of the central pain pathway in man: the conscious appreciation of pain. Brain 80:606-622.

Bushnell MC, Craig AD (1993) Nociceptive- and thermoreceptivespecific neurons in a discrete region of the monkey lateral thalamus. Soc Neurosci Abstr 19:1073.

Bushnell MC, Duncan GH (1987) Mechanical response properties of ventroposterior medial thalamic neurons in the alert monkey. Exp Brain Res 67:603-614.

Bushnell MC, Duncan GH (1989) Sensory and affective aspects of pain perception: is medial thalamus restricted to emotional issues? Exp Brain Res 78:415-418.

Bushnell MC, Duncan GH, Tremblay N (1993) Thalamic VPM nucleus in the behaving monkey. I. Multimodal and discriminative properties of thermosensitive neurons. J Neurophysiol 69:739-752.

Butkevich IP, Malysheva VV, Kassil VG (1987) Evoked potentials in the parafascicularis complex of the rabbit thalamus during peripheral noxious stimulation. Neurophysiology 18:554-558.

Casey KL (1966) Unit analysis of nociceptive mechanisms in the thalamus of the awake squirrel monkey. J Neurophysiol 29:727-750.

Casey KL, Morrow TJ (1983) Ventral posterior thalamic neurons 
differentially responsive to noxious stimulation of the awake monkey. Science 221:675-677.

Chudler EH, Anton F, Dubner R, Kenshalo DR Jr (1990) Responses of nociceptive SI neurons in monkeys and pain sensation in humans elicited by noxious thermal stimulation: effect of interstimulus interval. J Neurophysiol 63:559-569

Coghill RC, Price DD, Hayes RL, Mayer DJ (1991) Spatial distribution of nociceptive processing in the rat spinal cord. J Neurophysiol 65:133-140.

Coghill RC, Talbot JD, Evans AC, Gjedde A, Meyer E, Duncan GH, Bushnell MC (1992) Human cerebral processing of noxious and innocuous stimuli. Soc Neurosci Abstr 18:386.

Coghill RC, Mayer DJ, Price DD (1993) The roles of spatial recruitment and discharge frequency in spinal cord coding of pain: a combined electrophysiological and imaging investigation. Pain 53:295309

Corbetta M, Miezin FM, Dobmeyer S, Shulman GL, Petersen SE (1991) Selective and divided attention during visual discriminations of shape, color, and speed: functional anatomy by positron emission tomography. J Neurossi 11:2383-2402.

Craig AD (1992) Organization of lamina I terminations in the posterior thalamus of the cynomolgus monkey. Soc Neurosci Abstr 18:385.

Craig AD, Wiegand SJ, Price JL (1982) The thalamo-cortical projection of the nucleus submedius in the cat. J Comp Neurol 206:28-48.

Dao-fen C, Hyland B, Maier V, Palmeri A, Wiesendanger M (1991) Comparison of neural activity in the supplementary motor area and in the primary motor cortex in monkeys. Somatosens Motor Res $8: 27-44$.

Deiber M-P, Passingham RE, Colebatch JG, Friston KJ, Nixon PD, Frackowiak RSJ (1991) Cortical areas and the selection of movement: a study with positron emission tomography. Exp Brain Res 84: 393-402

Dong WK, Ryu H, Wagman IH (1978) Nociceptive responses of neurons in the medial thalamus and their relationship to spinothalamic pathways. J Neurophysiol 41:1592-1613.

Dong WK, Salonen LD, Kawakami Y, Shiwaku T, Kaukoranta EM, Martin RF (1989) Nociceptive responses of trigeminal neurons in SII-7b cortex of awake monkeys. Brain Res 484:314-324.

Dostrovsky JO, Guilbaud G (1988) Noxious stimuli excite neurons in nlucleus submedius of the normal and arthritic rat. Brain Res 460: 269-280.

Dostrovsky JO, Guilbaud G (1990) Nociceptive responses in medial thalamus of the normal and arthritic rat. Pain 40:93-104.

Dostrovsky JR, Tasker RR, Wells SEB, Lee L (1990) Pain evoked by stimulation in human ventrobasal thalamus. Proc Neurobiol Nociception 41

Douglass DK, Carstens E, Watkins LR (1992) Spatial summation in human thermal pain perception: comparison within and between dermatomes. Pain 50:197-202.

Drevets WC, Videen TO, MacLeod AK, Haller JW, Raichle ME (1992) PET images of blood flow changes during anxiety: correction. Science 256:1696.

Duclaux R, Kenshalo DR Sr (1980) Response characteristics of cutaneous warm receptors in the monkey. J Neurophysiol 43:1-15.

Evans AC, Marrett S, Collins L, Peters TM (1989) Anatomical-functional correlative analysis of the human brain using three dimensional imaging systems. SPIE 1092:264-274.

Evans AC, Marrett S, Torrescorzo J, Ku S, Collins L (1991a) MRIPET correlation in three dimensions using a volume-of-interest (VOI) atlas. J Cereb Blood Flow Metab 11:A69-A78.

Evans AC, Thompson CJ, Marrett S, Meyer E, Mazza M (1991b) Performance evaluation of the PC-2048: a new 15-slice encoded crystal PET scanner for neurological studies. IEEE Trans Med Imaging 10:90-98.

Evans AC, Marrett S, Neelin P, Collins L, Worsley K, Dai W, Milot S, Meyer E, Bub D (1992) Anatomical mapping of functional activation in stereotactic coordinate space. Neuroimage 1:43-53.

Feindel W (1961) Response patterns elicited from the amygdala and deep temporoinsular cortex. In: Electrical stimulation of the brain (Sheer DE, ed), pp 519-532. Austin: University of Texas.

Foltz EL, Lowell EW (1962) Pain "relief" by frontal cingulumotomy. J Neurosurg 19:89-100.

Fox PT, Mintun MA (1989) Noninvasive functional brain mapping by change-distribution analysis of averaged PET images of $\mathrm{H}_{2}^{15} \mathrm{O}$ tissue activity. J Nucl Med 30:141-149.
Fox PT, Burton H, Raichle ME (1987) Mapping human somatosensory cortex with positron emission tomography. J Neurosurg 67:3443.

Fox PT, Mintun MA, Reiman EM, Raichle ME (1988) Enhanced detection of focal brain responses using intersubject averaging and change-distribution analysis of subtracted PF.T images. J Cereb Blond Flow Metab 8:642-653.

Friedman DP, Murray EA (1986) Thalamic connectivity of the second somatosensory area and neighboring somatosensory fields of the lateral sulcus of the macaque. J Comp Neurol 252:348-374.

Friedman DP, Murray EA, O’Neill JB, Mishkin M (1986) Cortical connections of the somatosensory fields of the lateral sulcus of miacaques: evidence for a corticolimbic pathway for touch. J Comp Neurol 252:323-347.

Frysinger RC, Harper RM (1986) Cardiac and respiratory relationships with neural discharge in the anterior cingulate cortex during sleep-waking states. Exp Neurol 94:247-263.

Gabriel M, Kubota Y, Sparenborg S, Straube K, Vogt BA (1991) Effects of cingulate cortical lesions on avoidance learning and training-induced unit activity in rabbits. Fxp Brain Res 86:585-600.

Ghosh S, Turman AB, Vickery RM, Rowe MJ (1992) Responses of cat ventroposterolateral thalamic neurons to vibrotactile stimulation of forelimb footpads. Exp Brain Res 92:286-298.

Gingold SI, Greenspan JD, Apkarian AV (1991) Anatomic evidence of nociceptive inputs to primary somatosensory cortex: relationship between spinothalamic terminals and thalanocortical cells in squirrel monkeys. J Comp Neurol 308:467-490.

Greenspan JD, Winfield JA (1992) Reversible pain and tactile deficits associated with a cerebral tumor compressing the posterior insula and parietal operculum. Pain 58:29-39.

Head H, Holmes $G$ (1911) Sensory disturbances from cerebral lesions. Brain 34:102-254.

Herron P, Dykes R (1987) The ventroposterior inferior nucleus in the thalamus of cats: a relay nucleus in the pacinian pathway to somatosensory cortex. J Neurophysiol 56:1475-1497.

Hoff EC, Kell JF, Carroll MN (1963) Effects of cortical stimulation and lesions on cardiovascular function. Physiol Rev 43:68-114.

Hurt RW, Ballantine HT Jr (1973) Stereotactic anterior cingulate lesions for persistent pain: a report on 68 cases. Clin Neurosurg 21: 334-351.

Hutchins KD, Martino AM, Strick PL (1988) Corticospinal projections from the medial wall of the hemisphere. Exp Brain Res 71:667672

Hyvärinen J, Poranen A, Jokinen Y (1980) Influence of attentive behavior on neural responses to vibration in primary somatosensory cortex of the monkey. J Neurophysiol 43:870-882.

Jones EG, Seavitt RY (1974) Retrograde axonal transport and demonstration of non-specific projections to cerebral cortex and striatum from thalamic intralaminar nuclei in rat, cat and monkey. J Comp Neurol 154:349-378.

Jones AKP, Brown WD, Friston KJ, Qi LY, Frackowiak RSJ (1991) Cortical and subcortical localization of response to pain in man using positron emission tomography. Proc R Soc Lond [Biol] 244:39-44.

Joseph J, Howland EW, Wakai R, Backonja M, Baffa O, Potenti FM, Cleeland CS (1991) Late pain-related magnetic fields and electric potentials evoked by intracutaneous electric finger stimulation. Electroencephalogr Clin Neurophysiol 80:46-52.

Kaufman EFS, Rosenquist AC (1985) Efferent projections of the thalamic intralaminar nuclei in the cat. Brain Res 335:257-280.

Kenshalo DR Jr, Isensee O (1983) Responses of primate SI cortical neurons to noxious stimuli. J Neurophysiol 50:1479-1496.

Kenshalo DR Jr, Giesler GJ, Leonard RB, Willis WD (1980) Responses of neurons in primate ventral posterior lateral nucleus to noxious stimuli. J Neurophysiol 43:1594-1614.

Kenshalo DR Jr, Chudler EH, Anton F, Dubner R (1988) SI nociceptive neurons participate in the encoding process by which monkeys perceive the intensity of noxious thermal stimulation. Brain Res 454: 378-382.

Kenshalo DR Jr, Thomas DA, Dubner R (1991) Primary somatosensory cortical lesions reduce the monkey's ability to discriminate and detect noxious thermal stimulation. Soc Neurosci Abstr 17:1206.

Kurata K, Wise SP (1988) Premotor cortex of rhesus monkeys-setrelated activity during 2 conditional motor tasks. Exp Brain Res 69: $327-343$.

Larson MA, McHaffie JG, Stein BE (1987) Response properties of 
nociceptive and low-threshold mechano-receptive neurons in the hamster superior colliculus. J Neurosci 7:547-564.

Lenz FA, Kwan HC, Kostrovsky JO, Tasker RR, Murphy JT, Lenz YE (1990) Single-unit analysis of the human ventral thalamic nuclear group. Brain 113:1795-1821.

Lenz FA, Seike M, Richardson RT, Lin YC, Baker FH, Khoja I, Yeager CJ, Gracely RH (1993) Thermal and pain sensations evoked by microstimulation in the area of human ventrocaudal nucleus $(\mathrm{Vc}) . \mathrm{J}$ Neurophysiol 70:200-212.

Lofving B (1961) Cardiovascular adjustments induced from the rostral cingulate gyrus. Acta Physiol Scand 53:1-82

Luppino G, Matelli M, Camarda RM, Gallese V, Rizzolatti G (1991) Multiple representations of body movements in mesial area 6 and the adjacent cingulate cortex: an intracortical microstimulation study in the macaque monkey. J Comp Neurol 31 1:463-482.

Maixner W, Dubner R, Kenshalo DR Jr, Bushnell MC, Olivéras J-L (1989) Responses of monkey medullary dorsal horn neurons during the detection of noxious heat stimuli. J Neurophysiol 62:437-449.

Matsumoto N, Sato T, Yahata F, Suzuki TA (1987) Physiological properties of tooth pulp-driven neurons in the first somatosensory cortex (SI) of the cat. Pain 31:249-262.

Melzack R (1973) The puzzle of pain New York: Basic.

Melzack R (1986) Neurophysiological foundations of pain. In: The psychology of pain, 2d ed (Sternbach RA, ed), pp 1-24. New York: Raven

Mclzack R, Cascy KL (1968) Sensory, motivational and central control determinants of pain: a new conceptual model. In: The skin senses (Kenshalo DR, ed), pp 423-443. Springfield, IL: Thomas.

Meyer E, Ferguson SG, Zatorre RJ, Alivisatos B, Marrett S, Evans AC Hakim AM (1991) Attention modulates somatosensory cerebral blood flow response to vibrotactile stimulation as measured by positron emission tomography. Ann Neurol 29:440-443.

Miletic V, Coffield JA (1989) Responses of neurons in the rat nucleus submedius to noxious and innocuous mechanical cutaneous stimulation. Somatosens Motor Res 6:567-587.

Mountcastle VB, Talbot WH, Sakata H, Hyvärinen J (1969) Cortical neuronal mechanisms in flutter-vibration studied in unanesthetized monkeys. Neuronal periodicity and frequency discrimination. J Neurophysiol 32:452-484.

Mufson EJ, Mcsulam M-M (1982) Insula of the old world monkey. II: Afferent cortical input and comments on the claustrum. J Comp Neurol 212:23-37.

Murray EA, Mishkin M (1984) Relative contributions of SII and area 5 to tactile discrimination in monkeys. Behav Brain Res 11:67-83.

Musil SY, Olson CR (1988) Organization of cortical and subcortical projections to anterior cingulate cortex in the cat. J Comp Neurol 272:203-218.

Pardo JV, Pardo PJ, Janor KW, Raichle ME (1990) The anterior cingulate cortex mediates processing selection in the Stroop attentional conflict paradigm. Proc Natl Acad Sci USA 87:256-259.

Penfield W, Boldrey E (1937) Somatic motor and sensory representation in the cerebral cortex of man as studied by electrical stimulation. Brain 60:389-443.

Penfield W, Faulk ME (1984) The insula. Brain 1:67-83.

Penfield W, Rasmussen T (1955) The cerebral cortex of man. New York: Macmillan.

Perl ER, Whitlock DG (1961) Somatic stimuli exciting spinothalamic projections to thalamic neurons in cat and monkey. Exp Neurol 3:256296.

Perlmutter JS, Lich LL, Margenau W, Buchholz S '(1991) PET measured evoked cerebral blood flow responses in an awake monkey. $J$ Cereb Blood Flow Metab 11:229-235.

Pons TP, Garraghty PE, Mishkin M (1992) Serial and parallel processing of tactual information in somatosensory cortex of rhesus monkeys. J Neurophysiol 68:518-527.

Price DD (1988) Psychological and neural mechanisms of pain. New York: Raven.

Price DD, Dubner R (1977) Neurons that subserve the sensory-discriminative aspects of pain. Pain 3:307-338.

Price DD, McGrath P, Rafii A, Buckingham B (1983) The validation of visual analogue scales as ratio scale measures for chronic and experimental pain. Pain 17:45-56.

Price DD, McHaffie JG, Larson MA (1989) Spatial summation of heat-induced pain: influence of stimulus area and spatial separation of stimuli on perceived pain sensation intensity and unpleasantness. J Neurophysiol 62:1270-1279.

Rausell E, Jones EG (1991) Chemically distinct compartments of the thalamic VPM nucleus in monkeys relay principal and spinal trigeminal pathways to different layers of the somatosensory cortex. J Neurosci 11:226-237.

Reiman EM, Fusselman MJ, Fox PT, Raichle ME (1989) Neuroanatomical correlates of anticipatory anxiety. Science 243:107 I-1074.

Roberts TS, Akert K (1963) Insular and opercular cortex and its thalamic projection in Macaca mulatta. Schweiz Archiv Neurol Neurochir Psychiatr 92:1-43.

Robinson CJ, Burton H (1980a) Somatotopographic organization in the second somatosensory area of $M$. fascicularis. J Comp Neurol 192:43-67.

Robinson CJ, Burton H (1980b) Organization of somatosensory receptive fields in cortical areas $7 \mathrm{~b}$, retroinsula, postauditory and granular insula of $M$. fascicularis. J Comp Neurol 192:69-92.

Robinson CJ, Burton H (1980c) Somatic submodality distribution within the second somatosensory (SII), 7b, retroinsular, postauditory, and granular insular cortical areas of $M$. fascicularis. J Comp Neurol 192:93-108.

Roland PE, Larsen B, Lassen NA, Skinhoj E (1980a) Supplementary motor area and other cortical areas in organization of voluntary movements in man. J Neurophysiol 43:118-136.

Roland PE, Skinhoj E, Lassen NA, Larsen B (1980b) Different cortical areas in man in organization of voluntary movements in extrapersonal space. J Neurophysiol 43:137-150.

Royce GJ, Mourey RJ (1985) Efferent connections of the centromedian and parafascicular thalamic nuclei: an autoradiographic investigation in the cat. J Comp Neurol 235:277-300.

Seitz RJ, Roland PE (1993) Vibratory stimulation increases and decreases the regional cerebral blood flow and oxidative metabolism: a positron emission tomography (PET) study. In: Imaging of the brain in psychiatry and related fields (Maurer $\mathrm{K}$, ed), in press.

Seitz RJ, Roland PE, Bohm C, Greitz T, Stone-Elander S (1991) Somatosensory discrimination of shape: tactile exploration and cerebral activation. Eur J Neurosci 3:481-492

Shima K, Aya K, Mushiake H, Inase M, Aizawa H, Tanji J (1991) Two movement-related foci in the primate cingulate cortex observed in signal-triggered and self-paced forelimb movements. J Neurophysiol 65:188-202.

Sikes RW, Vogt BA (1992) Nociceptive neurons in area 24 of rabbit cingulate cortex. J Neurophysiol 68:1720-1732.

Sinclair RJ, Burton H (1991) Neuronal activity in the primary somatosensory cortex in monkeys (Macaca mulatta) during active touch of textured surface gratings: responses to groove width, applied force, and velocity of motion. $J$ Neurophysiol 66:153-169.

Sokoloff L (1991) Brain energy metabolism: cell body or synapse? In: Ciba Foundation symposium 163, Exploring brain functional anatomy with positron tomography, pp 43-56. New York: Wiley.

Stein BE, Price DD, Gazzaniga MS (1989) Pain perception in a man with total corpus callosum transection. Pain 38:51-56.

Talairach J, Tournoux P (1988) Co-planar stereotaxic atlas of the human brain. New York: Thieme.

Talbot JD, Marrett S, Evans AC, Meyer E, Bushnell MC, Duncan GH (1991) Multiple representations of pain in human cerebral cortex. Science 251:1355-1358.

Talbot JD, Duncan GH, Bushnell MC, Villemure J-G (1993) Evaluation of pain perception after anterior capsulotomy: a case report. IASP Abstr 1:464.

Thomas GJ, Slotnick BM (1963) Impairment of avoidance responding by lesions in cingulate cortex in rats depends on food drive. J Comp Physiol Psychol 56:959-964.

Tremblay N, Bushnell MC, Duncan GH (1993) Thalamic VPM nucleus in the behaving monkey. II. Response to air-puff stimulation during discrimination and attention tasks. J Neurophysiol 69:753763.

Vaccarino AL, Melzack R (1989) Analgesia produced by injection of lidocaine into the anterior cingulum bundle of the rat. Pain 39:213219.

Vierck CJ, Luck MM (1979) Loss and recovery of reactivity to noxious stimuli in monkeys with primary spinothalamic cordotomies, followed by secondary and tertiary lesions of other cord sectors. Brain 102:233-248.

Vierck CJ Jr, Greenspan JD, Ritz LA (1990) Long-term changes in 
purposive and reflexive responses to nociceptive stimulation following anterolateral chordotomy. J Neurosci 10:2077-2095.

Vogt BA, Pandya DN, Rosene DL. (1987) Cingulate cortex of the rhesus monkey: I. Cytoarchitecture and thalamic afferents. J Comp Neurol 262:256-270.

Vogt BA, Sikes RW, Vogt LJ (1993) Anterior cingulate cortex and the medial pain system. In press.

White JC, Sweet WH (1969) Pain and the neurosurgeon: a forty-year cxpcricncc. Springficld, IL: Thomas.

Wise SP, Strick PL (1984) Anatomical and physiological organization of the non-primary motor cortex. Trends Neurosci 7:442-446.
Worsley KJ, Evans AC, Marrett S, Neelin P (1992) A three-dimensional statistical analysis for $\mathrm{CBF}$ activation studies in human brain J Cereb Blood Flow Metab 12:900-918.

Yasui Y, Itoh K, Kamiya H, Ino T, Mizuno N (1988) Cingulate gyrus of the cat receives projection fibers from the thalamic region ventral to the ventral border of the ventrobasal complex. J Comp Neurol $274: 91-100$

Young GB, Blume WT (1983) Painful epileptic seizures. Brain 106: 537-554. 